\title{
Next Generation Public Safety and Emergency Technologies
}

\author{
Camilla Bonde, Reza Tadayoni and Knud Erik Skouby
}

Center for Communication, Media and Information Technologies (CMI)

Aalborg University Copenhagen, Denmark

Email: \{bonde; reza; skouby\}@cmi.aau.dk

Received: January 2015; Accepted: January 2015

\begin{abstract}
The paper researches the existing European standards for Public Safety and Emergency (PSE) services (also called Public Protection Disaster Relief "PPDR") 1 , and identifies based on user studies in Denmark conflicts between the current deployments of the standards and the user requirements.

The aim is further to identify the potentials of new technologies for PSE. The paper deals with policy and technology frameworks, regulatory issues and in particular the spectrum issues in the current PPDR deployments in the EU countries. The paper draws on the results and concepts developed in two EU-projects. ${ }^{2}$ Experience from research projects are used to discuss new possible solutions to the problems. We look at the development in other major

\footnotetext{
${ }^{1}$ PPDR is a broader definition. In Europe, the radio communications networks used by public safety and emergency services will normally be used to provide Public Protection ("PP"). As the trend in some parts of Europe is to allow non-public safety organisations that could be involved in major emergencies and disasters (for example transportation, utilities, military, etc.) to operate on the same networks as used by public safety organisations, it is logical that provision could be made on these networks (issue of terminals) to other agencies providing Disaster Relief ("DR").

${ }^{2}$ U-2010 (www.u-2010.eu/) and Chorist (www.chorist.eu), the ideas behind the MESA project and the Danish Strategic Research-financed FUSE project.
}

Journal of NBICT, Vol. 1, 43-72.

doi: 10.13052/NBICT.2015.003

(C) 2015 River Publishers. All rights reserved. 
markets and draw on developments on the Japanese and the US markets, when it comes to the deployment of $\mathrm{LTE}^{3}$.

Keywords: Mobile standards for PSE/PPDR, TETRA, LTE, spectrum management, deployment of standards, path dependence, lock-in and irreversibility in the decision-making process.

\section{Introduction}

The current digital TETRA-system for PPDR in Denmark named "SINE" has shown important shortcomings in relation to the critical needs that the PPDRusers request not only in relation to basic needs for critical communications (dynamic group calls, indoor coverage and cross border radio communication facilities) but also for critical mobile broadband communication services. The paper draws on the user studies, results and concepts developed in a Danish research project, RESCUE in 2012. The main research question in this paper is: Why has this situation with serious shortcomings developed and what are the specific consequences. We identify the existing problems based on a case study and user studies, the new requirements from the PPDR sector and the new possibilities to combine the existing TETRA technologies in Europe with the state of the art technologies. The aim is to discuss, how to meet the new essential requirements in the post analogue and post first generation digital era.

Today many advanced countries establish the necessary frameworks for development of new radio communication technologies. However, new research is highly needed to find the most optimal use of the relevant technologies and enable right decision making in this field. Examples of new supplementing technologies to PSE/TETRA are LTE technology and standalone nomadic technologies. An important issue is the spectrum designated for the PPDR market, which is a necessary precondition to enable introduction of the new supplementary technologies on the market.

New radio communication technological developments, including digitalization of broadcasting and the extensive demand for new mobile broadband

\footnotetext{
${ }^{3}$ LTE ("Long Term Evolution"), marketed as 4G LTE, is a standard for wireless communication of high-speed data for mobile phones and data terminals. It is based on the GSM/EDGE and UMTS/HSPA network technologies, increasing the capacity and speed using a different radio interface together with core network improvements. (https://sites.google.com/site/lteencyclopedia/home).

${ }^{4}$ Abreviation for SIkkerhedsNEttet (in English: Secure network).
} 
communication services call for rethinking of allocation, allotment and assignment of spectrum in Europe. Emergence of new technologies, the convergence process and the regulatory framework including refarming of the current spectrum bands to more socio-economic valuable use (the so-called "digital dividend") are some important elements in this discussion. Intensive work is going on by suppliers trying to harmonise frequencies for PPDR services in Europe in the 700-800 MHz bands facilitating an increase of the market for broadband services based on the LTE technology.

Spectrum within the duplex bands 380-385 MHz/390-395 MHz (Former NATO band) has been harmonised throughout Europe for PSE services, already identified by the former ERC Decision ERC/DEC(96)01 ${ }^{5}$. In Europe the ETSI standards TETRA, with its TETRA Enhanced Data Service (TEDS) according to EN 302 561, has for almost a decade been expected to provide wide band data applications for PSE radio communications (ECC/DEC/(08)05, 2008).

The ERC Decision amended 2011 that covers Wide Band Digital Land Mobile PMR/PAMR systems ${ }^{6}$ addresses the use of the bands $410-430 \mathrm{MHz}$, 450-470 MHz and 870-876/915-921 MHz, which are planned for applications within the land mobile service. "Although the Decision does not specifically designate particular frequency sub-bands to facilitate Wide Band Digital Land Mobile PMR/PAMR systems the ECC Decision is linked to the general frequency strategies as outlined in the Strategic Plan for PMR/PAMR for the period until 2013 (ECC Report 25)."

Similarly, parts of the frequency bands are not designated for PPDR applications outside Europe. The frequencies used outside Europe in ITU Regions 2 \& 3 (America and Asia broadly speaking), are not available in Europe. Within the European PSE frequency band TETRA became the preferred choice of technology. Although the TETRA market also covers traditional PMR and PAMR users, the PSE market is the largest and most significant. $^{7}$

In the US about $12 \mathrm{MHz}$ of the so-called digital dividend spectrum in the 700-800 MHz bands has been allocated for PPDR services (Trust, 2012). They expect providers to employ LTE for high-speed data and video applications.

\footnotetext{
${ }^{5} \mathrm{~A}$ harmonised frequency band to be designated for the introduction of the Digital Land Mobile System for the Emergency Services.

${ }^{6}$ ECC Decision of 19 March 2004 on the availability of frequency bands for the introduction of Wide Band Digital Land Mobile PMR/PAMR in the $400 \mathrm{MHZ}$ and 800/900 MHZ bands (ECC/DEC/(04)06) amended 26 June 2009, amended 09 December 2011.

${ }^{7}$ http://www.tandcca.com/assoc/page/12329
} 
Project 25 (P25 or APCO-25) has been the preferred standards for digital radio communications for use by federal, state/province and local public safety agencies in North America to enable them to communicate with other agencies and mutual aid response teams in emergencies ${ }^{8,9}$. In this regard, P25 fills the same role as the European TETRA protocol, although not interoperable with it. ${ }^{10}$

The upcoming LTE technology is also in many parts of Europe discussed as being the future technology for Wide Band Digital Land Mobile PMR/PAMR instead of TEDS, but no harmonised frequency bands have explicitly been designated for PPDR services in Europe to facilitate this development. Motorola, Ericsson, Alcatel-Lucent, Airbus and other companies have developed solutions for the PPDR sector based on LTEtechnology. However, the ETSI organisation has stated that the TETRA standards will continue to evolve to provide additional enhancements as driven by user needs, technology innovations and other parallel standard developments. ETSI has as, a consequence of this, no plans to develop a new technology standard for the use by large traditional PMR user organisations ${ }^{11}$.

According to TCCA ${ }^{12}$ the organisation of traditional PMR users, organisations will always require private PMR networks because public networks (like LTE, UMTS, GSM networks) cannot adequately provide the required coverage, grade of service during busy periods and high levels of reliability. Besides TCCA states that the public networks will not be able to provide the basic needs such as wide area fast call-set up all informed nets (group calls), Direct Mode Operation (DMO) and high levels of secure encryption for voice and data." ${ }^{13}$ However, LTE technology is increasingly being adopted by PSE agencies worldwide to improve decision making and operational efficiency in PSE operations, driven by the demand for data intensive applications such as end-to-end mobile video transmission. ${ }^{14}$

\footnotetext{
${ }^{8}$ The technology has also been used in Australia, New Zealand, Brazil, Canada, India and Russia. There were 660 P25-networks deployed in 54 countries by mid-2004.

${ }^{9}$ http://en.wikipedia.org/wiki/Project_25

${ }^{10} \mathrm{http}: / /$ en.wikipedia.org/wiki/Project_25

${ }^{11} \mathrm{http}: / /$ www.tandcca.com/about/page/12320

${ }^{12}$ TCCA "TETRA Critical Communication Association".

${ }^{13} \mathrm{http}: / /$ www.tandcca.com/about/page/12320

${ }^{14} \mathrm{https}$ ://sites.google.com/site/lteencyclopedia/public-safety-lte\#TOC-2.-Uplink-BudgetComparison
} 


\section{Structure of the Paper}

The paper first describes the theoretical framework (Section 3) and then the applied methodology (Section 4). Then follows a detailed outline of the context in which the TETRA standard was developed (Section 5) and the existing implementation of PPDR standards in Europe (Section 6). The challenges and shortcomings of the TETRA standards are addressed in Section 7; the digital dividend and PSE in Section 8. The potentials of new technologies are dealt with in Section 9 and 10. The conclusion and discussion of the findings and further research are in Section 11.

\section{The Theoretical Framework}

In economics, the theoretical standardization literature has mainly dealt with market exclusion. It has focused on two questions: "Under what conditions will a market standardize?" and, "Given that standardization takes place, will the market necessarily standardize on a good, or perhaps even the best standard?" (Cowan, 1992). According to Cowan the short answers are that in a wide variety of circumstances the market will lock in to one single technology; and that in an equally wide variety of circumstances it needs not necessarily abstractly be the best, even if there is consensus about what 'best' means. The main reasons for this are according Arthur, (Arthur, 1989) and Cowan, increasing returns to adoption and the reduction of technological uncertainty.

As one standard gets ahead in terms of providing solutions to technical difficulties and being broadly explored, there will be a tendency to stick with it. ${ }^{15}$ As further dealt with under Section 5 the technical ETSI-standardization of TETRA for PSE services in EU took place through the entire European market adopting one single set of standards for digital land mobile radio communication.

Pursuant to the fact that there was never developed other European ETSI standards for PSE services, than the TETRA standards, the EU harmonised frequency band in 380-400 MHz became tied to the TETRA standards for those countries that implemented the ERC/DEC(96)01. ${ }^{16}$ This nearly meant

\footnotetext{
${ }^{15}$ High Technology and the Economics of Standardization by Robin Cowan http:// www.cgl.uwaterloo.ca/ racowan/HighTechStand.html

${ }^{16}$ The Electronic Communications Committee (ECC) develops common policies and regulations in electronic communications for Europe, and is a focal point for information on spectrum use. Its primary objective is to harmonise the efficient use of the radio spectrum resources across Europe (http://www.cept.org/files/1047/CEPT\%20Leaflet-Feb2013.pdf).
} 
an entire market exclusion; all other technologies than TETRA were effectively driven from the PSE market.

The window for effective public policy interventions in the standardization process is typically limited. "Increasing returns means that when the market has" chosen a path "it becomes increasingly difficult to change this path meaning that policy intervention is most effective early in the process. This is the time, though, in which uncertainty is greatest and likelihood that mistakes are made, are highest (Cowan, 1992).

The initial stage of an infrastructure formation is characterized by the deliberate and successful design of technology-based services. The next generation technology will typically transfer across domains and locations resulting in variations on the original design, as well as the emergence of competing systems. The Infrastructures typically form only when these various systems merge, characterized by gateways allowing dissimilar systems to be linked into networks. In this stage, the standardization and inter-organizational communication techniques are critical. As multiple systems assemble into networks, early choices constrain the options available moving forward, creating path dependence (Paul N. Edwards, 2007) and (Hommels, 2010).

"Path dependence refers to the idea that past events keep influencing the developmental path or trajectory of a technology" (Hommels A. T., 2010) and, e.g., closes the window for intervention. Path-dependence typically develops over a longer period of time and as such means that local, short term contingencies can exercise lasting effects (MacKenzie, 1999).

Technological change is always path dependent in the sense that it builds on, and takes for granted, what has gone before. Today's choices constrain tomorrow's possibilities (Paul N. Edwards, 2007). They tend to become embedded in institutional and technological arrangements, and as they were, locked into a specific developmental path. This can make it difficult to change them later on (Vrancken, 2008).

Earlier research on the use of innovations tends to point out that the user adopts the innovation as defined by suppliers (Swan \& Clark, 1992). The technology might be used in various ways by different people, leading to different outcomes. Hence, there is no linear path between the design of a technology, its use and its impacts (Oostveen, 2007).

Hence, it is difficult to predict what the effects of a certain technology will be not only because of different adaptions and interpretations, but also because of the power structure of society as discussed by among others, Green and Davey (Oostveen, 2007). Technology is neutral outside society, but the development of technology is a result of choices made by powerful people 
representing certain social elites, such as the armed forces, bureaucracy and corporate power (Green, 2002). The technology the elite develop and sponsor affects the society to which it is transferred.

The development of the technology is a result of the priorities of the elites who sponsor its development, rather than representing the society as a whole. Therefore, biases not only arise from the way in which tools and technologies are used, but are already embodied in particular technologies. "Wrapped in the blanket of technological development and processes are gender, social, political, cultural, and economic factors, and power relations; all designed to influence the conception, design and use of technology" (Davey, 1995)" (Oostveen, 2007).

\section{The Methodology}

The deployment of a TETRA system in Denmark for PSE is chosen as a case for implementation of PSE technology and public intervention, because the Danish approach to the deployment of TETRA is an illustrative example of the role of decision-makers in large mobile radio communication network projects.

The arguments in this paper build on data from archival research, e.g. by analysing reports, correspondence between those who were involved in decision making process and the selected users and authorities to lead the implementation process, minutes of meetings (e.g. meetings between high ranked officials of the national police and other ministries etc.) to give an insight into the Danish decision-making process in relation to the deployment of the nationwide PSE TETRA-system.

We further analyse key decisions made by the Danish government, the national telecom agency and the national police as well as the Ministry of Justice in relation to the implementation of TETRA in Denmark. We use a path dependency and lock-in approach to describe the tendency which accounts for the choice of future technology on PPDR services in light of the spectrum policy decisions and strategic industrial alliances are taken into consideration in accordance with the next generation network.

\section{The Context in Which the TETRA-Standards Evolves and Is Applied}

\subsection{The General Context of a Mobile Communication Standard}

The development of a mobile communication standard takes place in a complex environment. This includes the regulatory, the institutional 
standardisation, the economic, the intellectual property, the market and the technological context.

There can be many ways for both the European and the national regulation of influencing the success of a mobile communication standard. The availability of sufficient spectrum and licenses, all mainly determined by regulation, can limit or encourage adoption of a standard.

There are many different standardisation bodies including the European CEPT ("the European Conference of Postal and Telecommunications Associations") and ETSI ("the European Telecommunications Standards Institute"); other regional and national authorities and the worldwide general telecom standardisation organisation ITU that can affect the success of a standard. It can be through the membership, the aim, the policy, the status of the standards they develop, their membership rules, the decision procedures and other procedures and rules that the influence flows.

Economists have identified a number of phenomena influenced by the compatibility that have an influence on the success of standards. The list includes network externalities, lock-in effects, path dependence and modularity.

The IPRs such as patents protect the technologies that are so close to the standard, that telecommunication equipment, which follows the standard de facto violates those IPRs. The companies holding those licenses can opt for a variety of strategies that can potentially damage the success of the standard. In this sense the standardisation bodies become victims of such companies' strategies (Bekkers, 2001).

\subsection{TETRA Becomes the Single European Harmonised Set of Digital Standards for Emergency Communication Adopted by ETSI}

\subsubsection{The standardisation}

The Schengen Treaty is the legal basis on which the mobile communications standardisation and frequency harmonisation process in the PSE sector were founded. The harmonisation of a common European-wide frequency band for public safety communications started within the Schengen Telecom Group $^{17}$. One of the Articles of the Treaty aimed at improving crossborder communications between police and customs units in the Schengen area.

\footnotetext{
${ }^{17}$ The Telecom group consisted of telecommunications experts from different countries within the Schengen area.
} 
In 1988 the EU Commission and ETSI began to develop a mobile digital radio system that would meet the requirement of the users. In the early days

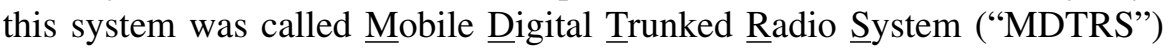
and the system was initially to be used by both public and private sectors and later primarily for the public safety and emergency sector. In 1992 it was renamed TETRA (Trans European Trunked Radio) and later TErrestrial Trunked RAdio, as global market potential became apparent.

The essential parts of the TETRA standardisation work (the TETRA Voice and Data (ETS 300 392) ${ }^{18}$ and TETRA Packet Data Optimised (PDO) (ETS $300393)^{19}$ ) was finalised in 1994 and approved in national voting at the end of $1995^{20}$.

The TETRA standards ${ }^{21}$ were developed to meet the needs of traditional $\mathrm{PMR}^{22}$ users $^{23}$ such as Public Safety (the police forces) and other civil users. ${ }^{24}$ This means it has a scalable architecture allowing economic network deployments ranging from single site local area coverage to multiple sites wide national area coverage. Some of the unique features of the TETRA standard were ${ }^{25}$ :

\footnotetext{
${ }^{18}$ ETS 300 392-1: "Radio Equipment and Systems (RES); Trans-European Trunked Radio (TETRA); Voice plus Data (V+D); Part 1: General Network Design" and ETS 300 392-2: "Radio Equipment and Systems (RES); Trans-European Trunked Radio (TETRA); Voice plus Data (V+D); Part 2: Air Interface (AI)".

${ }^{19}$ ETS 300 393-1, April 1996 (ETSI European Telecom Standard) on Radio Equipment and Systems (RES); Trans-European Trunked Radio (TETRA); Packet Data Optimized (PDO); Part 1: General network design.

${ }^{20} 22$ countries voted for the approval and none against it.

${ }^{21}$ The ETSI TETRA Standards consist of European Telecommunication Standards (ETSs) and ETSI European Standards (ENs):ETS/EN 300392 series (latest update in 2012), TETRA Voice + Data ETS 300393 series (TETRA Packet Data Optimized - all now historical), ETS/EN 300394 series (latest updated in 2012), TETRA Conformance testing specification, EN 300395 series (TETRA Speech Codec for full-rate traffic channel) ETS/EN 300396 series (latest updated in 2012) Technical Requirements for Direct Mode Operation (DMO), EN 300 812 series (Subscriber Identity Module (SIM) interface), EN 301, 302 \& 303 series TETRA Lawful Interception interface, EMC standards, End-to-end encryption, harmonized ENs for TETRA and for LM radio equipment according to RTTE Directive (plus Historical documents on: Attachment requirements for TETRA terminal equipment, Harmonized for TAPS) se further: http://www.oborneconsulting.co.uk/TETRA_Standards/ETSI_TETRA_Standards.htm

${ }^{22} \mathrm{PMR}$ is sometimes called Professional Mobile Radio and was developed for business users who need to keep in contact over relatively short distances with a central base station/ dispatcher - a typical example is a taxi company.

${ }^{23} \mathrm{http}$ ://www.etsi.org/website/technologies/tetra.aspx

${ }^{24}$ Transportation, utilities, Military, Commercial \& Industry.

${ }^{25}$ http://www.etsi.org/website/technologies/tetra.aspx
} 
- Group calls (Wide area fast call set-up).

- Direct Mode Operation (DMO) allowing communications between radio terminals independent of the network.

- High level voice encryption to meet the security needs of public safety organisations.

- Priority call (An emergency call facility that gets through even if the system is busy).

- Full duplex voice for PABX and PSTN telephony interconnection.

Besides meeting the needs of traditional PMR user organisations, the TETRA standard has also been developed to meet the needs of Public Access Mobile Radio ("PAMR") operators.

There is, however, a big difference between PMR and PAMR. PMR ("Professional or Private Mobile Radio") is intended for business operations, a PMR network is operated on a "closed user group" basis. PMR is designed for short call holding times which enables a large number of users to be accommodated within a particular frequency allocation. PAMR ("Public Access Mobile Radio") provides PMR type services to different users usually on a subscription basis, mostly on trunked network systems. ${ }^{26}$

PMR is clearly also different from public radio telephone technologies (e.g. "GSM" and "UMTS") as the operational needs of public radio telephone subscribers are very different from those of most PMR users. For instance, important PMR requirements that cannot be satisfied by the public radio telephone system are, among other things, fast channel access, direct mobileto-mobile communication also called direct mode operation ("DMO"), open channel and flexible group organisation (also mentioned as dynamic group calls) with various possibilities of individual and group calling facilities. ${ }^{27}$

To meet the user requirements at the time of the implementation (1995), the standard should ensure the following user requirements: (i) Interoperability between networks, (ii) A common air interface ensuring that any terminal that complies with the standard can be used with any network, (iii) Facilities include both secure speech and data and (iv) The standard is designed for easy introduction into existing mobile radio frequency band which would allow roaming between geographically separated networks.

Both European and national radio administrations and the European cooperation organisation in post and telecommunications, CEPT/ECC, had made tangible initiatives to strengthen and ensure the possibility to implement

\footnotetext{
${ }^{26} \mathrm{http} / / /$ www.erodocdb.dk/Docs/doc98/Official/Pdf/Rep052.pdf

${ }^{27}$ (ERC), 1997, p. 1.
} 
compatible radio communications systems between emergency services in EU Member States in accordance with the co-operation provision of the Schengen Convention above.

With the combined expertise from the EU Commission, the experts from ETSI and the co-operation of manufacturers, users, operators and industry experts, the first standards (TETRA) for the PMR communications system were ready in 1995 to enable manufacturers to design their radio communications equipment to interoperate successfully.

\subsubsection{A harmonised frequency band for emergency services in Europe}

One of the main problems of the former analogue PMR and PAMR networks was that often different frequency bands were used in different countries. The lack of one single market for terminals and infrastructure increased prices and often made cross-border communication impossible (international roaming). Partly due to these limitations with the analogue networks the importance of finding a single harmonised frequency band in Europe was a high priority among TETRA actors from the very beginning.

The police forces were eager to find harmonised frequency bands, if not for all TETRA applications then at least for their own public safety networks. The $380-400 \mathrm{MHz}$ band has always been considered to be an attractive candidate, because in all EU countries except France, this frequency band was used by NATO. If NATO would agree on emptying and releasing this frequency range for public safety, a single frequency band for TETRA would be available in all European countries.

In 1991 the Schengen Telecom group (also called "The Telecom Working Party") of the Signatories to the Schengen Treaty contacted the European Radio communications Committee ("ERC") that requested CEPT identified some harmonised spectrum for exclusive use by the police and security services across Europe. ${ }^{28}$

This request resulted in the Recommendation T/R 02-02 E (Bonn 1993) which was adopted by the ERC in 1993. Following discussion with CEPT, NATO did eventually agree in freeing this frequency for TETRA, but under the condition that it would be used for public safety network only. NATO agreed that initially 2 × $3 \mathrm{MHz}$ with an additional $2 \times 2 \mathrm{MHz}$, if required, based on a

\footnotetext{
${ }^{28}$ Harmonisation of frequencies for police and security services in Europe, Oslo, December 1991, European Radio communications Committee (ERC) within the European Conference of Postal and Telecommunications Administrations (CEPT).
} 
$10 \mathrm{MHz}$ duplex separation in the virgin frequency band 380-400 MHz would be made available for emergency services under certain conditions. ${ }^{29}$

This resulted in a set of ERC/ECC decisions that have been accepted and widely implemented by national administrations to ensure access to radio frequencies for emergency and public safety services in a single network, consisting of the 380-400 MHz frequency band.

In conformity to this condition, ERC adopted a recommendation that public safety network should have frequencies in the $380-400 \mathrm{MHz}$ band. This led to the fact that the ERC considered it necessary to reserve the frequency band for a single harmonised digital land mobile communications system for emergency communications. By the decision DEC (96)01 of 7 March 1996 taken by the ERC the frequency band $380-400 \mathrm{MHz}^{30}$ was released from NATO and designated for emergency and security purposes ${ }^{31}$.

It is stated in the ERC Decision of 7 March 1996 "on the harmonised frequency band to be designated for the introduction of the Digital Land Mobile System for the Emergency Services" (ERC/DEC/(96)01:

1. "[T] designate the bands $380-385 \mathrm{MHz}$ and $390-395 \mathrm{MHz}$ as frequency bands within which the requirements of the digital land mobile system be met[.]"

2. "[T]hat for the purpose of this Decision a single harmonised digital land mobile standard for emergency services, adopted by ETSI, shall be used in the designated frequency bands[.]"

The reason for this was, according to the decision, that the designation of an emergency frequency band implied that the spectrum within the frequency band 380-400 MHz must be used for emergency purposes. This granted TETRA operators and manufacturers of TETRA equipment adequate security around the frequency distribution and assurance that the frequencies in the emergency band were used for emergency purposes so that the industry could make the necessary investments in a common European technology standard,

\footnotetext{
${ }^{29}$ European Radio communication Committee ERC Decision of 7 March 1996 on the harmonised frequency band to be designated for the introduction of the Digital Land Mobile System for the Emergency Services (ERC/DEC/(96)01).

${ }^{30}$ The frequency bands $380-383 \mathrm{MHz}$ and $390-393 \mathrm{MHz}$ for use by a single harmonised digital land mobile system for emergency services and the whole or appropriate parts of the frequency bands 383-385 MHz and 393-395 MHz, if required, for use by a single harmonised digital land mobile system.

31 "ERC Decision of 7 March 1996 on the harmonised frequency band to be designated for the introduction of the Digital Land Mobile System for the Emergency Services" (ERC/DEC/(96)01).
} 
cf. Section 5.2. The decision showed, moreover, that this not only implies a harmonisation of spectrum, but also included a requirement for a single harmonised digital land mobile standard for emergency services, defined by ETSI, for emergency services, cf. also Section 5.2 above.

Furthermore, the Air-Ground-Air radio communication spectrum of the Emergency Services was harmonised by identifying the frequencies 384.800-385 and 394.800-394 MHz for the Air-Ground-Air operations. This was done first by approval of ERC Decision (01)20 in 2001 and repeated by approval of new Electronic Communications Committee (ECC - a merger of ERC and ECTRA in 2001) Decision (06)05-2006 - that supersedes $\mathrm{ERC} / \mathrm{DEC} /(01) 20$, but maintains the same harmonised core band definition. ${ }^{32}$

To extend the harmonised cross-border communication capabilities further to cover also Direct Mode radio communications (DMO, direct terminal to terminal (or mobile relay repeaters) without the help of networks, the ERC approved ERC Decision (01)19 in 2001 to identify the frequencies 380-380.150 and 390-390.150 MHz for the DMO of Digital Land Mobile Systems for the Emergency Services. ${ }^{33}$

The Direct mode-requirement was complicated in relation to the TDMA (Time Division Multiple Access) system of TETRA that requires precise time synchronisation between the elements that are involved in the communication. This timing is sent from the base stations to all the terminals. The DMO requirement required some extra work in relation to the standardisation to make these additions acceptable to users other than those public safety users, by including so-called managed direct mode, for example. While a nonmanaged direct mode features fulfils the needs of the public safety users, this includes a potential risk for commercial operators as the network is not involved in those communications, and therefore the network operator cannot charge its users. Whereas the managed DMO in the network is kept informed about the direct mode calls and can charge them to their subscribers.

The ERC decisions are, however, not automatically binding. European member states need to decide to implement ERC decisions in their national regulation to make them binding, but by 2001, 26 European nations had set aside the frequency band designated in the ERC decision for single harmonised digital land mobile communications for emergency communications.

The principles established through decisions that are implemented by the various countries are primarily shown through their frequency plans. The

\footnotetext{
${ }^{32} \mathrm{ERC} / \mathrm{DEC} /(01) 20$ and $\mathrm{ECC} / \mathrm{DEC} /(06) 05$.

${ }^{33} \mathrm{ERC} / \mathrm{DEC} /(01) 19$.
} 
commitment by CEPT member countries to implement the ERC decision was a clear indication that the relevant frequency bands were made available in a timely manner and at a European level to facilitate the development of a common European standard for emergency communication services.

The ERC and ECC Decisions listed above have been widely implemented by the EU and CEPT member states to produce a continent wide platform of harmonised radio frequencies for the use of the emergency services (see Appendix 1).

It should further be noted, that even if some administrations have stated not to implement the ERC/DEC/(96)01, the governments may still be using the $380-400 \mathrm{MHz}$ band for the digital radio communication of their public safety and security agencies. This is true e.g. in the case of Sweden that has built a 380-400 MHz TETRA network.

For TETRA-Civil other frequencies have been found in $410-430 \mathrm{MHz}$ and the $450-470 \mathrm{MHz}$ and even in the $800 \mathrm{MHz}$ band. CEPT/ERC confirmed on March 7, 1996 that civil TETRA networks would have to be accommodated in one of the three different frequency bands ERC/DEC (96)04. TETRA equipment such as terminals was however mainly made in the frequency band $380-400 \mathrm{MHz}$ for PSE-users and in the $410-430 \mathrm{MHz}$ for civil traffic. Around 2005 semi-dual band terminals or mini-wideband terminals were produced, but only in the frequency range in $380-430 \mathrm{MHz}$, and not between the ranges 380-400 MHz and 450-470 MHz.

\section{European Implementations of Emergency Network Based on TETRA in a Common Spectrum Band (380-400 MHz)}

In the late 1990s many European Governments decided to replace their older analogue radio systems ("MPT-1327 systems") and other legacy PMR systems with a more advanced digital radio communication systems based on the TETRA-standard. Most European countries have either already implemented or have decided to implement digital radio networks for Public Safety and Security (PSS) agencies as listed in the table in Appendix 2.

Within a single decade and despite its complex, multilevel decisionmaking structures Europe agreed upon and implemented a continent-wide common frequency and a common communications standard based on TETRA technology. Together, frequency and standard form the regulatory basis for 
comprehensive interoperability of public safety organisation communications systems in Europe.

The European decision on the deployment of TETRA ${ }^{34}$ created path dependence for the subsequent line of decisions on the PSE area. In, e.g., Denmark and the Netherlands we can see a path dependence from the existing technology and frequency settings in relation to the future decision on technology, frequency and supplier for a PPDR-network (for the Netherlands, see Hommels, 2010); in Denmark it is visible in the final implementation of a PPDR mobile communication system ("SINE") 35 based on the TETRA technology (the "SINE-project").

The European governments are commonly using the $380-400 \mathrm{MHz}$ frequency allocations always when deploying a government radio network for PSE. It is actually very difficult to identify a West-European government, who would not be using the $380-400 \mathrm{MHz}$ frequencies when deploying digital radio communications system for its PSE agencies. This fact can be understood as indication on how seriously the European governments actually follow the articles of the Schengen Convention in "coordinating their programmes for the procurement of communication equipment, with a view to installing standardised and compatible communications systems" as stated in Article $44(2)(d)$ of the Schengen Convention.

\section{The Challenges and Shortcomings of TETRA}

The existing TETRA system in Denmark has shown important shortcomings in relation to both fundamental user requirements such as dynamic group calls, a slow push to talk and indoor coverage (cf. our research with users deriving from the RESCUE project). Furthermore the group call functionality does not function if the professional user makes an individual call because it blocks the terminal. Therefore the professional users in the police force are obliged not to use their TETRA terminals for individual calls, but only for group calls, to prevent the terminals from being blocked if there is an important group call. This means that the police force mainly uses their public mobiles based on either UMTS or GSM due to the very few group calls. The fire fighters that have more group calls hardly have no indoor coverage for their hand portable terminals and therefore the use of the TETRA terminal is also limited among them. Instead the fire fighters also use their smart phones or other phones based on the public mobile network.

This illustrates that the success of a standard is affected by the organisational set-up in the implementation; how the implementation takes place; how 
the implementation of the standard meet the requirements from specific users supposed to be empowered by the implementation. The success is further affected by the organisational team that implements the standard, the size of the market, the existence of proprietary standards and including whether all or part of the standard is implemented and even a part of the suppliers technology.

\section{Digital Dividend Spectrum and PSE}

This section provides a short discussion of the 'digital dividend spectrum' and alternative applications of this band, with focus on the use of the band for PSE applications and services.

The digital dividend spectrum is the part of the spectrum that can be taken from broadcast allocations and used for other type of services. In one of the Communications from the European Commission, the digital dividend is defined as 'the spectrum over and above the frequencies required to support existing broadcasting services in a fully digital environment, including current public service obligations' (European Commission 2007).

The discussion of access to the digital dividend spectrum is mainly driven by the digital transition of terrestrial broadcasting, which radically changes the spectrum situation. Depending on different technological parameters a spectral efficiency of 6 to 8 times can be achieved when we go from analogue to digital.

The digital dividend discussion represents an obvious conflict of interest between on the one hand the traditional broadcasters and on the other players from other communication sectors. The conflict over access to the valuable spectrum resources has been there for many years and has been intensified in different phases of the technological development. The market organisation of radio and TV broadcast services has historically been dominated by either monopoly organisation (national or local) or in few cases by markets having few competing broadcasters. The spectrum scarcity argument has been used as one of the reasons for this market organisation model and for not giving resources to other communication sectors. However, the scarcity argument was challenged from very early on $^{36}$ and the basis for spectrum scarcity has been changed radically by the transition from analogue to digital.

\footnotetext{
${ }^{36}$ See among others Coase R.: "The federal Communication Commission”, The journal of Law \& Economics, October 1959 and (Noam 1991).
} 
Also in the digital era the broadcasters fight to keep as much spectrum as possible for broadcast purposes. In the US, for example, the strong broadcasters began to market HDTV at the end of the 1980s to replace NTSC ${ }^{37}$ trying to hold on the extra TV channels allotted for television services in every city. This resulted in FCC's provision of spectrum without cost to virtually all of the current television broadcasters to provide for parallel transmission of 'advanced television services' 38 in the 1996 Telecommunication Act. This raised huge resistance from other market actors who were interested in the spectrum, especially from the "land mobile" and computer industry.

The issues relating to the digital dividend are dealt with in a range of different international and national organisations and settings. ITU and its Radio Conferences are the most important events in this regard. ITU's Regional Radio communication Conference in Geneva in 2006 (GE06) took some important decisions regarding the distribution of the digital dividend between the different applications, primarily broadcasting and interactive communications (e.g. mobile broadband).

The process toward reallocating the $800 \mathrm{MHz}$ spectrum in the EU can be illustrated in the followings steps:

- In GE06 the possibility for using ' $800 \mathrm{MHz}$ band' for other than TV services was established.

- World Radio Conference 2007 (WRC 07) decided to allocate the ' $800 \mathrm{MHz}$ band' for mobile services.

- In $2009 \mathrm{CEPT}^{39}$ developed 3 reports $(30,31,32)$ about the $800 \mathrm{MHz}$ band, which were commissioned by the EU.

- Since 2008 there have been a number of EU recommendations and communications to prepare the $800 \mathrm{MHz}$ band for other uses.

- In 2009 Analysis Mason developed a detailed study on 'exploiting the digital dividend', commissioned by the EU. (Mason 2009).

- On 6th May 2010 EU made a decision on technical requirements when a member country decides to use the spectrum for electronic communication services, including mobile broadband.

\footnotetext{
${ }^{37}$ This was a lobbying strategy against Land Mobile. By the end of the 1980 s, actors from "Land Mobile" industries applied for these resources to use them for mobile communication systems. Broadcasters, led by the National Association of Broadcasters (NAB), came up with the argument that they needed these resources to introduce HDTV.

${ }^{38}$ Later Digital HDTV services.

${ }^{39}$ The European Conference of Postal and Telecommunications Administrations.
} 
When the reallocation of the $800 \mathrm{MHz}$ band was a reality, the major question was who should have access to the new spectrum? One paradigm was to assign the spectrum to services for specific use; following the example of Japan and the US where the digital dividend spectrum was assigned for Intelligent Transportation Systems (ITS) and PSE. The other paradigm, which mainly has been used in the EU was to assign resources to commercial mobile broadband operators, and refer the specific uses, like PSE, to negotiations with commercial operators and obtain specific requirements by setting terms and conditions for the use of the spectrum.

The above mentioned Mason analysis report (Mason 2009) gives the most comprehensive discussion of the issue and points to a number of different deployment scenarios. Analysis Mason identifies 5 potential uses of digital dividend frequencies in the EU:

- Digital terrestrial TV (DTT)

- Broadcast Mobile TV

- Commercial wireless broadband services

- Wireless broadband services for public protection and disaster relief

- Services ancillary to broadcasting

The issue has also been taken up by other scholars and consultancy firms, including WIK and Aegis, who developed a larger report on Public safety and security (PSS) - commissioned by the industry companies, Cassidian and Motorola: 'Safety First - Reinventing the Digital Divide in Safeguarding Citizens (WIK \& Aegis, 2008). The report indicate amongst others the need for mobile broadband in the sector: "Communication needs of Public Safety operations are evolving and broadband communications are rapidly becoming more essential."

In a Danish research project called FUSE (FUture Service InfrastructurE) the different aspects of digital dividend spectrum is analysed in details and in particular with regards to the $800 \mathrm{MHz}$ band in Europe. The conclusion was that when it comes to use of this band for other uses, none of the societal uses will get specific allocations of this spectrum in the EU (Henten et al 2011). Huge lobbying activities have been there to get access to part of the spectrum, e.g., for PSE services, without positive results. The solution for getting access to the spectrum for, e.g., PSE uses is identified by the experts and relevant stake holders as putting specific QoS and availability requirements on some of the commercial networks and to use the capacity of the networks for the PSE uses. 
As illustrated above, in the EU the $800 \mathrm{MHz}$ band has been re-allocated from broadcast to mobile broadband. The band has been/is being assigned for commercial mobile broadband in different countries. In the US on the other hand, the focus has been on the $700 \mathrm{MHz}$ band and part of the $700 \mathrm{MHz}$ band has been reallocated and assigned for PSE services. The US already had spectrum at $700 \mathrm{MHz}$ allocated to public safety, including two blocks of $5 \mathrm{MHz}$ spectrum allocated for broadband (Mason 2010). "In February 2012, legislation was passed allocating the so-called "D Block" (a further two $5 \mathrm{MHz}$ blocks adjacent to the previous broadband spectrum) to public safety, establishing from August 2012 the First Responder Network Authority or FirstNet to set up a nationwide, interoperable public safety broadband network and providing USD 7 billion to help with the build-out." (Mason 2012).

The next step in the EU is also to look at the reallocation of the $700 \mathrm{MHz}$ band. The starting point here is the decision taken in the World Radio Conference 2012 (WRC 12), where a second Digital Dividend in $700 \mathrm{MHz}$ has been allocated to mobile services from 2015 . While in the $800 \mathrm{MHz}$ allocation and assignments there was not agreement in the EU on creating space for specific PSE assignments, the situation is different in the discussions of the reallocation and assignments of the $700 \mathrm{MHz}$ band. Here the EU is focusing on obtaining harmonized spectrum for PSE Mobile broadband applications. "The need for action to address spectrum for mission-critical networks is reflected in Europe's five-year spectrum plan (Radio Spectrum Policy Program), recently agreed by the European Parliament." (Mason 2012). The EU has commissioned CEPT to study the issue and "CEPT has set up PT49, which is working on Radio Spectrum for Public Protection and Disaster Relief (PPDR), in particular broadband high-speed data applications and harmonized spectrum." (Mason 2012).

\section{LTE $^{40}$}

As discussed above, the European PSE standards as TETRA are facing different technological challenges. One of the most important challenges is delivery of mobile broadband services and applications. The need for advanced audio and video applications and services in the mission critical operation has forced the sector to look for alternative solutions to replace the current

\footnotetext{
${ }^{40}$ Long-Term Evolution, a standard for mobile phones and data terminals. It is based on the GSM/UMTS network technologies, but with an IP-based network architecture. It is increasing the increasing the capacity and speed. The standard is developed by the 3GPP (3rd Generation Partnership Project.).
} 
standards as TETRA or complement them to enable development of advanced PSE services.

An important issue is the spectrum available for the PSE market, which is a necessary precondition to enable introduction of the new supplementary technologies on the market.

In the following we introduce a short discussion of the requirements that can be fulfilled by a new possibility to combine the existing TETRA technology with the state of the art mobile technologies to meet essential requirements in the post analogue and post first generation digital era.

LTE has been one of the candidates for some years and its position is strengthened after it was chosen for mobile broadband for emergency services in the US. "In January 2011, the FCC issued an order and proposed rule-making that requires all $700 \mathrm{MHz}$ public safety mobile broadband networks to use a common air interface, specifically LTE, to support roaming and interoperable communications" (Mason 2012).

Obviously LTE has the bandwidth capacity needed to meet the requirements of broadband applications and services and when it is used in the lower UHF band, e.g., the $700 \mathrm{MHz}$, where the spectrum has optimal propagation characteristics it can be used to cover larger areas in a cost efficient way. This makes LTE a favourite standard when a combination of narrowband and broadband standards is suggested. This makes a case for implementing TETRA as the narrow band mission critical service with LTE as the broadband platform.

However, if LTE is going to replace TETRA it must be capable of meeting other requirements from the PSE applications and services; as indicated in this paper, some of the important parameters are:

- Fast set-up calls

- Possibility for group call

- Direct mode operation for cases when the terminals have not access to the network

- Access control and priority regimes

The first and last requirements are definitely within the scope of the LTE standard; LTE has historically low set up time; low latency and includes the possibility for access control and priority. The two other requirements, group call and direct mode are, however, crucial issues to be solved if LTE is going to replace the current PSE standards in Europe.

LTE is based on the Internet Protocol (IP) and here the possibility for group call obviously exists. However, if this meets requirement of mission critical applications must be studied more in details. The Direct Mode is not 
a standard feature of the LTE standard and this represents a technology gap when it comes to PSE applications. For example P3 Communication in a recent white paper cannot see implementation of Direct Mode in LTE in the foreseeable future (P3 Communication 2012). However, important players like QUALCOMM are working on adding the feature to the standard, but further studies are needed to identify how LTE will be developed with respect to the implementation of direct mode ${ }^{41}$. Following the US implementation of LTE will give answers to some of these questions.

\section{Nomadic Ad Hoc Networks}

The LTE track is, however, not the only possible option for upgrading from the TETRA system. A different option is to develop a novel communications architecture with the vision to complement current modern mobile emergency systems, offload them in the congested situations and add more bandwidth right at the scene of incidence. As a vision it addresses the situation where a highly efficient radio cell is established with equipment brought into a scene of incident along with the first responders. The idea (advanced, e.g. in a Danish research project, RESCUE) is to develop an adaptive, secure and high capacity nomadic hot-spot to manage, control and offer advanced wireless communication and positioning in a complex disaster area for PPDR ("Public Protection Disaster Relief") services - the relevant scenes can be major metropolitan fires; underground traffic disasters; major traffic incidents; disasters related to major concerts or sports events.

The contribution is related to the integration of multiple systems and technologies to meet the PSE requirements in such situations. Using, e.g., a middleware layer to combine heterogeneous position sensor inputs in combination with 3D geo-spatial information, the special conditions in the disaster area can be tackled and uncertainty in location and navigation support accounted for.

The hot-spot infrastructure is aimed to be self-configuring and selfadjusting in relation to both users and the network. The RESCUE solution is an innovative, complete end-to-end infrastructure that integrates communications and localization and addresses several main challenges in the PSE environment: a) localization of possible victims in the disaster area b) establish communication with and locations of the rescue personnel across the involved emergency services c) keep continuously operational communication links

\footnotetext{
${ }^{41}$ See for example "LTE Standards Body Considers Study on Public-Safety Direct Mode" in http://www.pscr.gov/about_pscr/press/broadband/broadband_press.php
} 
open to the rescue personnel under surveillance d) register automatically the presence of rescue personnel as they arrive at the scene and e) locate the rescue personnel continuously.

The RESCUE proposal adds an advanced on-site disaster relief capability to existing mobile TETRA mission critical voice communication systems and uses the obvious qualities of LTE for back haul/communication to/from the incident site.

\section{Conclusion and Discussion}

The success or failure of a standard depends on various factors related to the implementation phase and the nature of the environment in which the standard has been developed and deployed and by whom the system has been supplied.

The deployment of a "pick and choose" standard is very much dependent on the organisations in charge for the enrolment of the standard and the chosen supplier, because various functionalities described by the standard can be left out by the supplier or because the deployment organisations have left it out for various reasons in the requirement specification during the purchasing phase.

A deployment of the PSE standard is only successful if the standard (and the deployment of the standard) meets the user requirements. If it does not either because of a wrong selection of the various functionalities that the PSE system must comply with; due to the lack of fulfilment of various requirements by the supplier; unforeseen development in requirements or a combination of these issues - it may result in the lack of gratification of basic critical needs. This may call for a faster replacement of an existing standard with a new competing or complementing standard that fulfils (partly or exclusively) the users' requirements, even though the existing PSE standard as such, if it was fully implemented and deployed, would have complied with the requirements of users.

The paper shows that path dependence for PSE services in Denmark was created long time before the actual TETRA systems were implemented due to the fact that the various ERC decisions concerning harmonisation of a common single frequency band in the mid-90s was implemented across Europe. This is in line with the theoretical discussion of path dependence where it is shown that path dependence is not only related to artefacts but is very much associated with organisational and social structures. An aspect of this is NATO's release of a frequency range that was based on the conditions that the allocation of the frequencies were designated to a single harmonized European ETSI standard for PSE services. As the various member states transposed this decision into 
their national regulation regimes it tied the spectrum to TETRA as TETRA was the only European standards for PSE services. This in turn strengthened and preserved the market situation with a single European harmonized ETSI standard for PSE. One of the ideas behind this technology intervention was exactly to create a single European-wide - and maybe even global - market for PSE communication products in an analogy with the successful GSMdevelopment.

The European market was created, but it has proven much more difficult to get it responsive to new user requirements than the ' $G$ '-expansion track on the general mobile market. One obstacle is the much smaller market size, another is the complicated PSE organisational structure. From a purely technological point of view there are answers to some of the new user requirements in the LTE track and in the 'hot spot' solution. A combination of these technologies may address the most important parameters in the new user requirements for PSE communication:

- Broadband capacity

- Fast set-up calls

- Possibility for group call

- Direct mode operations for cases when the terminals have not access to the network

- Access control and priority regimes

The TETRA technology cannot provide these facilities and it is therefore not an option to introduce them stepwise - in that sense the PSE development is locked in. The users and the suppliers are waiting for an official decision whether the LTE will be harmonised worldwide for the provision of critical services - either in terms of dedicated PPDR networks or by use of public mobile networks. As it looks today this will, however, only be a partial solution. Based on the experience with the TETRA implementation, it is, however, crucial that actors responsible for the technology intervention on this area are aware of the - at least temporary - irreversibility lock in that is created.

\section{References}

[1] Bekkers, R. (2001). Mobile Telecommunications Standards: GSM, UMTS, TETRA and ERMES.

[2] Bijker, W. E., \& Law, J. (1997). Shaping Technology/building Society: Studies in Social Technical Change. In W. E. Bijker, \& J. Law, Shaping 
Technology/building Society: Studies in Social Technical Change. MIT press Cambridge, Massachusetts.

[3] Brey, P. (1997). Social Constructivism for Philosophers of Technology: A Shopper's Guide. Retrieved June 24, 2013, from http://scholar.lib.vt.edu/: http://scholar.lib.vt.edu/ejournals/SPT/v2_n3n $4 \mathrm{html} / \mathrm{brey} \cdot \mathrm{html}$.

[4] CEPT report. (1997, November 13). Methodology for the assessment of PMR systems in terms of spectrum efficiency, operation and implementation. European Conference of Postal and Telecommunications Administrations (CEPT), Brussels, Belgium.

[5] Commission, E. (2007). 'Reaping the Full Benefits of the Digital Dividend in Europe', COM (2007).

[6] Communication, P. (2012, June). 'LTE for Critical Communications Drivers, Benefits and Challenges'.

[7] Cowan, R. (1992). New technology at the outset. Social forces in the shaping of technological innovations. In High technology and the economics of standardization. (pp. 279-300). New York: Westview.

[8] David, P. A. (2000, June). Path dependence, its critics and the quest for 'historical economics'.

[9] ECC/DEC/(08)05. (2008, June 27). ECC/DEC/(08)05 on the harmonisation of frequency bands for the implementation of digital Public Protection and Disaster Relief (PPDR) radio applications in bands within the 380-470 MHz range. CEPT. Retrieved June 18, 2012, from http://www.erodocdb.dk/docs/doc98/official/pdf/ECCDec0805.pdf.

[10] Edwards, P. N. (2007). Understanding Infrastructure: Dynamics, Tensions and Design.

[11] Garud, R., \& Karnoe, P. (2013). Path dependence and creation. Psychology Press.

[12] Green, L. (2002). Communication, Technology and Society. London: Sage Publications Ltd.

[13] Henten Anders, W. I. (2011). FUSE report: The battle for the digital dividend spectrum. CMI Aalborg University.

[14] Hommels, A. (2005). Unbuilding Cities. Obduracy in Urban Sociotechnical Change. The MIT Press, Cambridge.

[15] Hommels, A. T. (2010, January-June). Beyond the "Point og No Return": Constructing Irreversibility in Decision Making on the Tetra Standard in Dutch Emergency Communication. International Journal of IT Standards and Standization Research, pp. 28-48. 
[16] J. Rajamäki, J. H. (2010). Robust Mobile Multichannel Data Communication for Rescue and Law Enforcement Authorities, Proc. of the 17th Symposium on Communications and Vehicular Technology in the Benelux. Twente. The Netherlands.

[17] Jakobs, K. (2000). Information Technology Standards and Standardization: A Global Perspective. Kindle Edition.

[18] Kirzner, I. (1992). The Meaning of Market Process: Essays in the Development of.

[19] Kvale, S. (2001). An Introduction to Qualitative Research Interviewing.

[20] MacKenzie, D. a. (1999). Introductory essay: the social shaping of Technology. In D. MacKenzie, \& J. Wajcman, Originally published in "The social shaping of Technology” (pp. 1-50). MacKenzie, D., \& Wajcman, J. (1999). Introductory Essay: the Social Shaping of Technology. In D. MacKenzie \& J. Wajcman (Eds.), The Social Shaping of Technology (pp. 3-27). Buckingham, UK: Open University Press.

[21] Margolis, S. E., \& Liebowitz, S. J. (n.d.). Path Dependence. Retrieved June 24, 2013, from www.utdallas.edu: http://www.utdallas.edu/ liebowit/palgrave/palpd.html.

[22] Mason. (August 14, 2009). Exploiting the digital dividend - a European approach', Report for the European Commission. Mason.

[23] Mason. (March 8, 2010). 'Public Safety mobile broadband and spectrum needs', Report for the TETRA Association. Mason.

[24] Oostveen, A.-M. (2007). Digital Academic Repository van de Universiteit van Amsterdam. Retrieved June 26, 2013, from http://dare.uva.nl/: http://dare.uva.nl/document/155296.

[25] Paul N. Edwards, P. A.-P.-P. (2007). Understanding infrastructure: Dynamics, Tensions, and Design. School of Information, University of Michigan: Report of a Workshop on "History \& Theory of Infrastructure: Lessons for New Scientific Cyberinfrastructures".

[26] Pinch, T. J.-4. (1984). The social construction of facts and artefacts: Or how the sociology of science and the sociology of technology might benefit each other. Social studies of science. In Social studies of science (pp. W. E. 399-441).

[27] Praeger, D. (2008, June 15). Our Love Of Sewers: A Lesson in Path Dependence.

[28] PSST. (2012). The PSST Vision for Public Safety Broadband Communications. Retrieved May 12, 2012, from http://www.psst.org/publicsafety network.jsp 
[29] R. Williams, R. B. (2004). Understanding the Evolution of Standards: Alignment and Regcongifuration in Standards Development and Implementation Arenes. EASST The European Association for the study of Science and Technology (pp. 1-16). The University of Edingburgh.

[30] Schumpeter, J. A. (1942). Creative destruction. Capitalism, socialism and democracy.

[31] Swan, J. A., \& Clark, P. (1992). Organizational decision-making in the appropriation of technological innovation: Cognitive and political dimensions. In T. \&. Francis, The European Work and Organizational Psychologist (pp. 103-127). CRC Press.

[32] Taylor, D. (2012, July 3). 'LTE ADVANCES IN PUBLIC SAFETY COMMUNICATIONS'. Retrieved from http://mason.analysysmason. com/News-and-Events/News/LTE-advances-in-public-safety-communi cations/

[33] Trust, P. S. (2012). www.psst.org. Retrieved May 1 May 2012, 2012, from The PSST Vision for Public Safety Broadband Communications: http://www.psst.org/future.jsp

[34] Vestergaard, G. (2012). Engineer. (C. Bonde, Interviewer).

[35] Von Hayek, F. A. (1948). Individualism and economic order: essays. p. University of Chicago Press.

[36] Vrancken, J. (2008). Internet addressing standards: A case study in standards dynamics driven by bottom-up adoption. The Dynamics of Standards, 68-81. 


\section{Appendix 1}

\begin{tabular}{|c|c|c|c|}
\hline COUNTRY & ERC/DEC/(96)01 & $|\mathrm{ERC} / \mathrm{DEC} /(01) 19|$ & ERC/DEC/(01)20 \\
\hline Austria & Yes & Yes & Yes \\
\hline Belgium & Yes & Yes & Yes \\
\hline Bulgaria & Yes & & \\
\hline Croatia & Yes & Yes & Yes \\
\hline Cyprus & Yes & Yes & Yes \\
\hline Czech Republic & & Yes & Yes \\
\hline Denmark & Yes & Yes & Yes \\
\hline Estonia & Yes & Yes & Yes \\
\hline Finland & Yes & Yes & Yes \\
\hline Germany & Yes & Yes Partly & Yes Partly \\
\hline Greece & Yes & & \\
\hline Hungary & Yes & Yes & Yes \\
\hline Iceland & Yes & Yes & Yes \\
\hline Ireland & Yes & Yes & Yes \\
\hline Italy & Yes & Yes & Yes \\
\hline Latvia & Yes & Yes & Yes \\
\hline Liechtenstein & Yes & Yes & Yes \\
\hline Lithuania & Yes & Yes & Yes \\
\hline Luxembourg & Yes & Yes & Yes \\
\hline Malta & Yes & & \\
\hline Moldova & Yes & & \\
\hline Netherlands & Yes & Yes & Yes \\
\hline Norway & Yes & Yes & Yes \\
\hline Poland & Yes & Committed & Committed \\
\hline Portugal & Yes & & \\
\hline Romania & Committed & & \\
\hline Slovak Republic & & Committed & Committed \\
\hline Slovenia & Yes & Yes & Yes \\
\hline Spain & Yes & Committed & Committed \\
\hline Sweden & & Committed & Committed \\
\hline Switzerland & Yes & Yes & Yes \\
\hline $\begin{array}{l}\text { The former Yugoslav Republic of } \\
\text { Macedonia }\end{array}$ & Yes & & \\
\hline Turkey & Committed & Committed & Committed \\
\hline United Kingdom & Yes & Yes & Yes \\
\hline
\end{tabular}

Figure 1 The implementation status of the said decisions in the member states is currently as indicated in the above table (data collected from the European Radio communications Office (ERO) website www.ero.dk September 2012). The word "Yes" in the table indicates that the national administration has declared having implemented the decision nationally 
70 C. Bonde et al.

\section{Appendix 2}

\begin{tabular}{|c|l|c|}
\hline COUNTRY & Type of network & Frequency band MHz \\
\hline Austria & Shared PSS, TETRA & $380-400$ \\
\hline Belgium & Shared PSS, TETRA & $380-400$ \\
\hline Bulgaria & Police, TETRA & $380-400$ \\
\hline Czech Republic & PSS & $380-400$ \\
\hline Denmark & Public Mobile Telephony & $380 / 400$ \\
\hline Estonia & Shared PSS, TETRA & $380-400$ \\
\hline France & Police & $380-400$ \\
\hline Finland & Shared PSS, TETRA & $380-400$ \\
\hline Germany & Shared PSS, TETRA & $380-400$ \\
\hline Greece & Shared PSS, TETRA & $380-400$ \\
\hline Hungary & Shared PSS, TETRA & $380-400$ \\
\hline Iceland & Shared PSS, TETRA & $380-400$ \\
\hline Ireland & PSS, in tendering & $380-400$ \\
\hline Italy & Shared PSS contract, TETRA & $380-400$ \\
\hline Lithuania & Shared PSS, TETRA & $380-400$ \\
\hline Netherlands & Shared PSS, TETRA & $380-400$ \\
\hline Norway & Shared PSS, TETRA, tendering & $380-400$ \\
\hline Poland & Regional TETRA & $380-400$ \\
\hline Portugal & Shared PSS, TETRA & $380-400$ \\
\hline Romania & PSS, TETRA + other & $380-400$ \\
\hline Slovak Republic & PSS & $380-400$ \\
\hline Slovenia & & $380-400$ \\
\hline Spain & PSS, TETRA + other & $380-400$ \\
\hline Sweden & Shared PSS, TETRA & $380-400$ \\
\hline Switzerland & PSS & $380-400$ \\
\hline Macedona & PSS, in tendering & $380-400$ \\
\hline United Kingdom & Shared PSS, TETRA & $380-400$ \\
\hline The former Yugoslav Republic & \\
\hline The ima & & \\
\hline & & \\
\hline & & \\
\hline & & \\
\hline & & \\
\hline & & \\
\hline
\end{tabular}

Figure 2 The implementation status of the countries that have decided to implement digital radio networks for public safety and Security agencies are listed in the table 


\section{Biographies}

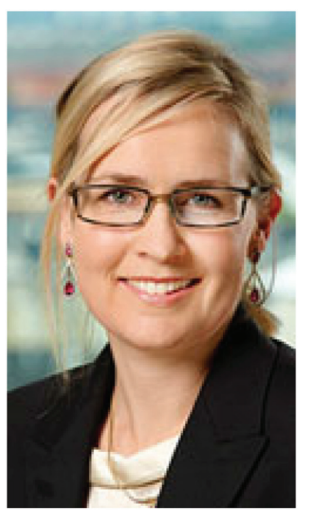

Camilla Bonde is a Ph.D. student at the Center for Communication, Media and Information Technology at Aalborg University in Denmark. She has a master of law form Aarhus University and Trinity College in telecommunications, procurement and EU law, and has been employed as a lawyer since 2000 (first in Dublin in Ireland and later in Copenhagen in Denmark). Her legal area has also been mainly IT/Telecom law, public procurement and competition law. Her working experiences with large public safety and emergency service contracts and infrastructure procurements have led her to the $\mathrm{PhD}$ studies in 2011. The studies focus mainly on the schism of having regulation requiring technology neutrality in technological dependent contexts. The research is focused on this inherent disharmony of conformity and why and how this influences technological solutions in a negative way.

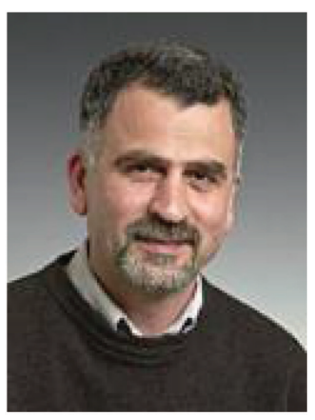

Reza Tadayoni (born 1962) is associate professor at CMI (Center for Communication, Media and Information Technologies) at Aalborg University. He 
holds aM.Sc.E.E. from DTU (Danish Technical University) specialized in broadband communication, and holds a PhD from DTU in the field of media convergence. His main research focus is on the ICT development and media convergence.Reza Tadayoni has participated in a number of Danish, European and international research projects and he has supervised a number of $\mathrm{PhD}$ projects and master and bachelor thesis, and he has published +100 of scientific papers and research reports.

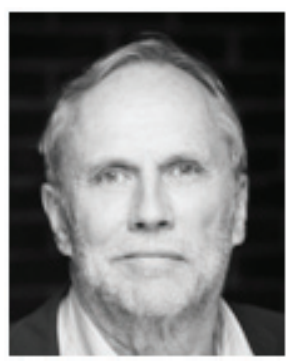

Knud Erik Skouby is professor and director of center for Communication, Media and Information technologies, Aalborg University-Copenhagen. Has a career as a university teacher and within consultancy since 1972. Working areas: Techno-economic Analyses; Development of mobile/ wireless applications and services: Regulation of telecommunications.

Project manager and partner in a number of international, European and Danish research projects. Served on a number of public committees within telecom, IT and broadcasting; as a member of boards of professional societies; as a member of organizing boards, evaluation committees and as invited speaker on international conferences; published a number of Danish and international articles, books and conference proceedings. Board member of the Danish Independent Research Council and the Danish Media Committee. Chair of WGA in Wireless World Research Forum; Special Advisor to GISFI; dep chair IEEE Denmark. 